DOI: 10.12731/2077-1770-2019-2-138-155

УДК 294.32

\title{
МЕДИТАТИВНАЯ ПРАКТИКА БЕЗМЯТЕЖНОСТИ (ZHI-GNAS) И ПРОНИКНОВЕНИЯ (IНАG-THONG) КАК ФОРМА ИЗМЕНЕНИЯ КАРТИНЫ МИРА
}

\author{
Неронова М.Ю., Неронов А.В.
}

В статье дается теоретический анализ медитативной практики тибетского буддизма (школа Гелуг) и формулируется объясняющая концепция, позволяющцая на основе западного рациионального дискурса понять суть практики в целом и отдельных ее элементов.

Цель: предложить научную конщепщию, объясняющую суть и содержание медитативной практики, представленной в трактате одного из основоположников тибетского буддизма Чже Цонкапа.

Метод и методология проведения работы: применялся метод аналогии, был использованы аксиологический подход.

Научная новизна: предложена оригинальная объясняющая конщепция, позволяющая на основе западного рачионального дискурса понять суть медитативной практики тибетского буддизма (икола Гелуг).

Результаты: была сформулирована теоретическая модель, позволяющая объяснить с позищий современного гуманитарного знания, проиессы, происходящие с сознанием адепта и результаты, достигаемые в ходе медитативной практики безмятежности и проникновения.

Область применения результатов: Полученнье результаты могут быть применены при изучении восточных духовных практик.

Ключевые слова: безмятежность (zhi-gnas); проникновение (ihagthong); картина мира; сочиализащия; легитимаџия; сощиокультурный гомеостаз; альтернация; идентичность.

\section{MEDITATIVE PRACTICE CALM ABIDING (ZHI-GNAS) AND HEIGHTENED INSIGHT (IHAG-THONG) AS THE FORM CHANGES OF THE WORLD VIEW}

\section{Neronova M.Yu., Neronov A.V.}

The article provides a theoretical analysis of the meditative practice of Tibetan Buddhism (Gelug school) and formulates an explanatory con- 
cept that allows to understand the essence of the practice in General and its individual elements on the basis of Western rational discourse.

Purpose: to propose a scientific concept explaining the essence and content of the meditative practice presented in the treatise of one of the founders of Tibetan Buddhism Je Tsongkhapa.

Methodology: The method of analogy was employed. Cultural analysis is based on using axiological approach.

Scientific noveltyan: original explanatory concept is proposed, which allows to understand the essence of meditative practice of Tibetan Buddhism (Gelug school) on the basis of Western rational discourse.

Results: the theoretical model was formulated, which allows to explain from the standpoint of modern humanitarian knowledge, the processes taking place with the consciousness of the adept and the results achieved in the course of meditative practice of calm abiding (zhi-gnas) and heightened insight (ihag -thong).

Practical implications: the results of the study can be applied in the study of oriental spiritual practices.

Keywords: calm abiding (zhi-gnas); heightened insight (ihag-thong); world view; socialization; legitimation; sociocultural homeostasis; alternation; identity.

Противопоставление восточной и западной форм духовности и соответствующих форм мышления давно стало привычной аксиомой в лоне западной философии и науки. Усилия философской компаративистики также не разрешили проблемы фундаментального различия между метафизическими системами Запада и Востока. Как писал В.К. Шохин: «В настоящее время, когда дуалистическая картина философского мира признана в основном уже устаревшей, а «сплошные параллели» достаточно поверхностными, появился известный скепсис в связи с легитимностью самой категории философии как общего знаменателя восточных и западных философских дробей...» [7, с. 2].

Видный советский и российский специалист по буддизму Ф.И. Щербацкой также скептически отзывался о попытках пони- 
мания индийской философии через поиски аналогий с западными учениями $[8,9]$. По этому поводу он пишет следующее «...всякое сравнение, ведущее за собой сравнительную оценку индийских умозрений не может избежать субъективности... Совпадения между результатами индийского и европейского мышления легко принимаются за подтверждение истинности на том основании, что истина одна, а ложь бесконечно разнообразна. Но так как нет почти ни одной западной системы, которая не встречалась бы в Индии, то сам по себе факт совпадения ничего не доказывает, так как на него могут ссылаться и дуалист, и монист, и скептик, и догматик, и реалист, и идеалист, и материалист, и спиритуалист» $[9$, с. 6].

Восточная философия продолжает оставаться во многом непонятной для современной западной мысли, поскольку она лежит за пределами дискурса европейской философии, а сравнение с западными вариантами или даже подробное толкование квалифицированных специалистов по восточным языкам не позволяют решить данную проблему. Чтобы адекватно понять ту же буддийскую философию необходимо «перевести ее на язык западного дискурса», а для этого необходимо сформулировать соответствующую научную концепцию, созданную на основе идей и понятий, лежащих в лоне западной научной традиции. При этом должна получиться релевантная объясняющая модель, позволяющая осознать то, что выбрано в качестве объекта исследования уже не как перевод или сравнение, а как понятную когнитивную систему со знакомой логикой и не менее знакомой терминологией. То есть, объяснение должно быть сделано на основе культурного кода, на котором строится дискурс европейской науки и философии.

В данной статье мы предлагаем рассмотреть духовную практику, известную как в буддизме, так и в некоторых школах индуизма, которую принято называть медитативной практикой. Речь идет об особом методе усвоения доктринальных принципов в ходе тщательно разработанных медитаций. В индуизме такая духовная практика известна как «Джняна-йога» или «Йога познания». Она встречается, например в даршане «санкхья», где все элементы материи пракри- 
ти должны быть не просто различены между собой, но и детально проанализированы как то, что не есть дух пуруша [6].

В нашей статье мы будем рассматривать одну из медитативных практик, включенную в Ламрим - Большое руководство к этапам Пути Пробуждения, важнейший сборник текстов тибетской школы Гелуг [4]. Система медитации, известная под названием Ламрим, согласно легенде, была основана в одиннадцатом веке великим тибетским святым Атишей, а затем развита основателем школы Гелуг Чже Цонкапа. Мы обратимся к практике «безмятежного проникновения», подробно описанной в трактате «Большое руководство к этапам пути пробуждения IV Этап духовного развития высшей личности (продолжение)» [5], которое, по сути, целиком посвящено разъяснениям метода буддийской медитации, основанного на особой форме однонаправленного мышления.

В указанной работе изложено учение о двух взаимосвязанных между собой духовных практиках, именуемых безмятежностью и проникновением. Первое понимается как сосредоточение ума на объекте медитации, а второе как размышление об этом объекте. Цонкапа так говорит об этом:

««Совершенно неотвлекающийся ум»-это сосредоточение мысли, относящееся к безмятежности, а «правильные размышления о духе и букве Дхармы»-это аналитическая мудрость, относящаяся к проникновению. Поэтому для осуществления всех достоинств двух Колесниц требуются оба: исследование при помощи аналитической мудрости и однонаправленное сосредоточение мысли на одном объекте. Посредством одного лишь закрепленного созерцания или только аналитического они не достигаются» [5, с. 4].

Далее даётся развёрнутое объяснение:

«То есть, избрав объектом созерцания какое-нибудь подходящее положение из двенадцати разделов Слова, [например] суть совокупностей [личности], - при помощи внимательности и бдительности поддерживают постоянное закрепление мысли на этом объекте, не допуская отклонений. При достижении таким способом естественного пребывания мысли на объекте, зарождаются радость и 
блаженство совершенной податливости тела и ума. Тогда самадхи становится безмятежностью [5, с. 7].

После достижения безмятежности наступает пора практики проникновения. «Что же такое проникновение?

То, что начинается исследованием и основательным исследованием Источников того же правильно продуманного [положения] Дхармы с тем же вниманием, с которым культивировалась безмятежность, а также основательным исследованием дхарм и завершается обширным познанием и мудростью, называется проникновением» $[5$, с. 10].

Чтобы обрести достаточную полноту понимания описанных практик, надо также познакомиться с правилами их осуществления. Их шесть.

\section{1. Пребывание в подходящей местности}

Здесь говорится о том, что местность должна быть безопасной, обладать возможностью получения пищи и одежды, «неболезнетворной», немноголюдной и тихой ночью, с наличием друзей и единомышленников.

\section{2. Малые желания}

Здесь даются указания не иметь привязанности к доброкачественной или изобильной пище, монашеской одежде и т.д.

\section{3. Довольствование [скудным]}

То есть, необходимо довольствоваться лишь тем, что есть, не желая лучшего.

\section{4. Отказ от многих дел}

Здесь необходимо отказаться от купли-продажи, чрезмерного общения, от изготовления лекарств, астрологии и «прочих дурных занятий».

\section{5. Чистая нравственность}

Здесь запрещается нарушение обетов и говорится о необходимости покаяния в случае, если обеты будут нарушены.

\section{6. Отказ от помыслов об [удовлетворении] желаний и прочем}

Здесь необходимо созерцать пагубность желаний в рамках учения Будды [5, с. 26-28]. 
Теперь можно подвести некоторые итоги, не вдаваясь в подробности дальнейшего изложения, касающегося нюансов практики, где рассматриваются психологические моменты, ошибки практикующих и т.п.

Итак, мы видим подробно изложенную идею о взаимодополняющих друг друга практиках (безмятежность и проникновение), имеем необходимые определения каждой из практик, объяснения относительно необходимости их последовательного применения, а также правила осуществления указанных практик. Данные практики, предназначены для буддийских монахов, удалившихся от суеты обыденной жизни с целью добиться самадхи, то есть, реализовать высшую цель буддистов - достигнуть состояния сознания Будды, как это изложено в восьмеричном пути.

На первый взгляд все достаточно понятно, однако эта понятность чисто внешняя и во многом обманчивая. Если внимательно проанализировать эту часть трактата, то появляются закономерные вопросы: что происходит с сознанием адептов при подобной практике, и, действительно ли практикующие достигают искомой цели?

Объяснения, приведенные в трактате, сводятся к тому, что безмятежное сосредоточение на объекте обеспечивает «податливость тела и ума», а также дарует радость и блаженство. Проникновение, как размышление об объекте, позволяет проникнуть в сущность этого объекта, без чего нельзя понять, каков он есть на самом деле [5, с. 14]. Последовательное выполнение указанных практик приводит к самадхи. Здесь невольно приходится идти на поводу автора, который излагает конкретную духовную доктрину в рамках буддизма, и просто запоминать его положения, пытаясь подстроить свой ум к логике соответствующей духовной традиции. Если мы встанем на сторону полного принятия буддизма, только тогда мы сможем перестроить и весь наш дискурс в соответствии с принципами учения Будды. Но тогда, для адекватного понимания буддийских концепций нам надо перестать быть самими собой и утратить собственную точку зрения на реальность. Необходимо как-то преодолеть возникшее противоречие. 
Для того чтобы сделать первый шаг на пути решения возникшей проблемы, попытаемся понять суть происходящего. Конечно, даже простые обыватели-буддисты знают основные положения учения Будды о спасении через достижение самадхи. Однако Цонкапа дает свое учение для «духовного развития высшей личности», как можно видеть из самого названия трактата. И по содержанию становится ясно, что изложенные практики предназначены не для мирян, а для монахов. Последние должны удалиться от обыденной суеты и полностью посвятить себя упражнениям в безмятежности и проникновении, то есть, в сосредоточении на нужных объектах и однонаправленном размышлении о них в рамках буддийской доктрины. Здесь предлагается не размышлять об объекте с целью его «истинного познания», как делали бы представители европейской философии и науки, а, по сути, преобразовать свое исходное знание об объекте в форму буддийского толкования о нем.

Понятно, что в поле буддийского дискурса даже простой обыватель не сомневается в том, что «поистине все есть пустота» и необходимо стремиться к спасению от колеса сансары, однако его знания являются поверхностными, так как несмотря на доктринальные установки, он продолжать жить, опираясь на ценности и смыслы обыденного существования. То есть, внешние знания о доктринальных принципах не могут определять мотивацию обычного мирянина, которого воспитывали как живущего в повседневной действительности, где упавший со скалы камень может привести к реальной травме или к смерти. Даже если же он ремесленник или купец, то его практический опыт, скорее, противоречит учению Будды, чем подтверждает его. Поэтому, такой человек, для достижения спасения должен обратиться к религиозным обрядам и ритуалам, а не к духовной практике, в которой достигается реализация состояния сознания, погруженного в нирвану. Преодолению разрыва между доктринальными принципами и обыденными знаниями, основанными на опыте повседневной жизни, должны способствовать практики безмятежности и проникновения. Для объяснения того, что при этом происходит с сознанием человека, 
мы можем обратиться к философским и научным знаниям европейской традиции.

Согласно результатам исследования современных гуманитарных наук (философии, социологии, психологии, культурологии), чтобы стать полноценным членом общества, любой человек с раннего детства проходит этапы социализации-инкультурации, поскольку не бывает абстрактных людей, но есть лишь такие, которые рождаются и воспитываются в рамках той или иной национальной культуры. Далее при анализе выделенной проблемы мы будем опираться на концепцию П. Бергера и Т. Лукмана, изложенную в их работе [1].

Получая воспитание, образование и личную идентичность в ходе социализации, всякий человек приобретает также и соответствующую картину мира (у названных авторов это «символический универсум» [1, с. 157-163]), через посредство которой он соотносится с реальностью. Сначала картину мира формируют в сознании ребенка его родители и близкие. Растущему человеку указывают на различные объекты и, давая им имена, объясняют, что это такое и как этим можно пользоваться. То же происходит и с правилами поведения, различными ценностями и так далее. Подобные объяснения, называемые легитимациями [1, С. 151-60], буквально сшивают смысловыми нитями всю формирующуюся картину мира социализируемых индивидов, придавая ей целостность и непротиворечивость, и связывают ее с социальной практикой. Благодаря объяснениям и примерам действий, полученным от многочисленных агентов социализации, все предметы и правила внешнего мира в сознании человека соединяются в единую систему мировоззрения и, мир становится таким, «каков он есть». Всеобщее признание основных компонентов единой картины мира придает последней силу объективной реальности, так происходит интернализация [1, с. 210 224] существующей картины мира в сознание личности. В дальнейшем сам человек начинает действовать в соответствии с усвоенным мировоззрением, подтверждая на практике свою картину мира, и придавая ей объективность. Этот процесс П. Бергер и Т. Лукман именуют экстернализацией. Благодаря процессам интернализации 
и экстернализации [1, с. 80-209] поддерживается социокультурный гомеостаз и идентичность. В одной из наших предыдущий статей мы вводили такое понятие как социокультурый гомеостаз [3]. Социокультурный гомеостаз предполагает, что в мире не должно быть того, чего нет в картине мира, и, наоборот, в картине мира нет ничего,чтобы не имело практического подтверждения в действительности. На основании чего можно сделать вывод, что картина мира во многом определяет идентичность личности.

Механизм социокультурного гомеостаза действует в любой культуре, независимо от времени, этноса или уровня ее развития. Существуют также картины мира, в которых для достижения необходимого равновесия, требуется применение дополнительных приемов. Речь идет о культурах, построенных в соответствии с вероучением мировых религий. Все мировые религии утверждают в качестве абсолютной основы мира духовную реальность, выходящую за границы опыта повседневной жизни, постулируя вторичный производный характер последней. Например, православная картина мира, отчасти могла найти воплощение в повседневной действительности, благодаря церкви и религиозной традиции, но самые важные фундаментальные положения (догмат о Троице, богоподобие человека и т.д.) не могли быть подтверждены и реализованы в поле обыденной жизни. Следовательно, для реализации подобных радикальных идей требовался особый вид практик, выходящих за пределы обыденности, но, тем не менее, существующих в рамках культурной действительности.

Преобладающей реальностью для людей является повседневный мир, и здесь возникает новая проблема. А. Щюц так пишет об этом: «Это мир физических вещей, в число которых входит и моё тело; это сфера моих перемещений, телесных операций; он оказывает мне сопротивление, преодоление которого требует приложения усилий; он ставит передо мной задачи, позволяет мне претворять мои планы; он позволяет мне достигать успеха или терпеть неудачу в достижении моих целей. Своими актами работы я включаюсь во внешний мир; я изменяю его, и эти изменения, хотя и спровоциро- 
ваны моей работой, могут быть пережиты и подвергнуты проверке не только мною, но и другими людьми... Я разделяю этот мир и его объекты с другими людьми; вместе с другими я имею общие для нас цели и средства; вместе с ними я работаю в многообразных социальных актах и взаимоотношениях, контролируя других и находясь под их контролем» [10, с. 421].

Таким образом, любой человек прошедший социализацию интернализирует ценности, цели и смысла, закрепленные в повседневной реальности, где правят «упрямые факты» материального мира, власть, богатство и прочая. А значит для того, чтобы практические реализовать фундаментальные положения мировых религий, он предварительно должен изменить мировоззрение согласно духу и букве доктрины, то есть, в соответствии с концепцией П. Бергера и Т. Лукмана произвести альтернацию личности. Под альтернацией они понимали особую радикальную форму направленной ресоциализации, результатом которой становилась новая измененная (альтернативная) форма личности [1, с. 254-262].

В наше время хорошо изучен феномен «альтернации личности» в рамках некоторых нетрадиционных религиозных движений (НРД), таких как Свидетели Иеговы, Церковь саентологии, Церковь объединения и т.д. Над вовлеченными в такие новорелигиозные организации неофитами производят действие по их ресоциализации с изменением картины мира, а, стало быть, и личности в целом, которая становится альтернативной той, что была раньше.

Культовая трансформация личности предполагает не только социально-психологическое изменение человека, но и трансформацию его мировоззрения, поскольку неофит должен принять культовую доктрину во всех ее моментах, вплоть до усвоения новой картины мира и соответствующей системы ценностей. Посмотрим, как это осуществляется в новых религиозных движениях, на примере Свидетелей Иеговы. В соответствии с доктриной иеговистов, мир гибнет, поскольку уже начался конец света. Все неправедные (не Свидетели Иеговы, разумеется) сгорят в огне светопреставления, зато праведники будут счастливо жить в обновленном мире, не ведая забот и стра- 
даний. Сами ценности Свидетелей Иеговы проистекают из образа гибнущего мира и несут в себе эсхатологическую окраску, подобную умонастроениям первых христианских общин, также ожидавших скорого конца света. Бог есть высшая ценность, а все прочее вторично. Этот земной мир сам по себе в отрыве от Бога не обладает ценностью, зато несомненной ценностью является «братство-сестринство» иеговистов, как община, единая в истинной вере. Все, что по ту сторону общины не представляет собой никакой ценности.

Основная работа по культовому изменению личности вовлекаемого начинается сразу за вербовкой, когда человек входит в культ на правах неофита. Неофит должен покинуть родных, друзей, знакомых (у саентологов, например, принято писать «письмо отказа») и жить только с представителями культа, которые понуждают его изучать доктрину и поступать в строгом соответствии с ее принципами. Прежняя жизнь в мире отныне рассматривается как «неистинная», а значит, не ценная, зато «новая жизнь» в рамках культовой группы выступает в качестве единственно правильной, ценной и наполненной смыслом. Изменяется и отношение к внешнему миру, который становится либо несовершенным, либо греховным, но в любом случае «инаковым», «чуждым». Свидетели Иеговы постоянно изучают Библию на собраниях, занимаются активной проповеднической деятельностью, трудятся на благо общины и четко следуют доктринально определенным правилам жизни. У иеговистов запрещены пьянство, курение, азартные игры, воровство, ложь, внебрачные половые отношения, гнев, насилие и так далее. Они всегда опрятно одеты и при контактах с людьми предпочитают улыбаться и вести себя учтиво. Однако основной принцип Свидетелей Иеговы, говорящий, что надо «жить в мире, но не быть его частью» ясно указывает на замкнуто оппозиционный характер культовых установок данного религиозного движения по отношению к обществу и его культуре.

При этом хорошо известно, что провести радикальную ресоциализацию с изменением картины мира, ценностей и самой идентичности человека возможно лишь в том случае, если неофит добровольно согласен пойти на это. Здесь, по сути, происходит перевоспитание человека, который согласен быть «ребенком», со сто- 
роны новых «духовных родителей». А потому необходимо порвать все связи с внешним миром, принять и изучить доктрину, а затем жить в соответствии с нею среди «братьев по духу и вере» [2].

Конечно, в приведенном примере описана групповая альтернация личности, где все изменения идентичности индивида производятся и поддерживаются коллективом адептов новой веры. Роль альтернируемого сводится, в основном, к согласию с доктриной и предложенным ему процессом личностной трансформации.

Перед теми, кто применяет буддийские практики для достижения поставленной цели стоит задача трансформировать собственное сознание на основе признанных текстов под руководством духовного учителя. Из приведенного ранее материала становится понятно, в чем состоит суть указанных духовных практик и для чего они предназначены.

Для достижения социокультурного гомеостаза, адепты практик безмятежности и проникновения производят особую форму культовой ресоциализации (альтернации), то есть создают новую идентичность, путем реализации в процессе медитации фундаментальных положений буддизма, и происходит это благодаря изменению приобретенной в ходе социализации картины мира. Исходя из полученного знания, мы можем дать ответ на поставленные ранее вопросы: что происходит с сознанием адептов при подобной практике, и, действительно ли практикующие достигают искомой цели?

Здесь важным является то, что удалось найти объясняющую концепция, которая позволяет адекватно понять суть медитативной практики, не прибегая к сравнениям, а используя для объяснения готовую научную концепцию, созданную в лоне европейского рационального дискурса.

Но вернемся к содержанию трактата Цонкапы и посмотрим, как работает данная концепция. Для этого обратимся к ранее упомянутым шести правилам осуществления практик, и попробуем выяснить, для чего они здесь приведены.

Шесть правил осуществления практик играют роль особых условий и требований, способствующих отрыву практикующего от по- 
вседневного мира и людей, в нем живущих, что практически всегда наблюдается при культовой ресоциализации (альтернации). Это же служит фактором настройки сознания практикующего на основные буддийские ценности. Выбор места, отказ от излишеств, «чистая нравственность» и так далее, все это соответствует трем принципам буддийского монашества: «Будда - Дхарма - Сангха», где под Дхармой понимается учение Будды, а под Сангхой - изолированная от мира община единомышленников. Как мы упоминали выше (рассматривая пример иеговистов), действительный отказ от обыденного мира, является необходимым условием альтернации, так как означает отказ не только от повседневного образа жизни, но и от целей, ценностей и смыслов, приобретенных в ходе социализации.

Теперь перейдем к самому процессу медитации. Там имеется следующая последовательность:

1. Выбор объекта медитации. Им может быть любой объект, например, структура человеческой личности.

2. Безмятежное сосредоточение на объекте.

3. Аналитическое проникновение в объект.

Сразу отметим, что смысл медитации состоит в том, чтобы любой объект был заново переосмыслен в духе буддийской доктрины. Никакого познания в смысле западного понимания этого феномена здесь не происходит, поскольку задача поставлена иная: сосредоточившись, например, на личности как на объекте, реализовать в сознании ее доктринальный смысл, а именно, что поистине нет никакой личности, а есть лишь иллюзия личности, поскольку это не более чем «узор светоносных дхарм в пустоте». Осуществляя практики безмятежности и проникновения, адепт стремился реализовать в своем сознании основные доктринальные положения буддизма, говорящие о том, что личность лишена самобытия так же, как и физическое тело человека, как и весь мир, являющийся в восприятии органами чувств или в уме. Но как это возможно реализовать, если восприятие мира остается прежним?

Да, восприятие остается прежним, но его элементы заново переосмысливаются. Как раз для этого необходимо последовательно 
связать безмятежность и проникновение. Здесь происходит процесс намеренной релегитимации, притом, в той же последовательности, в какой легитимация производилась агентами социализации (например, родителями) над социализируемыми индивидами в период их детства. Сначала внимание детей намеренно привязывали к определенному объекту, которому давали имя. Так происходило сосредоточение внимания на объекте. Притом сам объект еще не был вписан в строящуюся картину мира и потому выступал в качестве единичного феномена без осмысленных связей с другими объектами. Затем агенты социализации начинали объяснять, чем является данный объект, какие он может выполнять функции, как он устроен и так далее. В результате, рассматриваемый объект связывался в сознании социализируемого индивида с другими объектами и процессами, постепенно получая значение неотъемлемой части взаимосвязанного мира.

Итак, во время безмятежности, внимание адепта сосредотачивается на объекте, вырванном из контекста связей с другими элементами картины мира. Теперь это некая абстрактная ментальная структура, лишенная суммы легитимирующих связей.

Следующий ход это проникновение. Теперь выделенный объект необходимо заново осмыслить, используя буддийскую доктрину. Так возникает новая легитимация как объяснение «сути объекта», но только «суть» эта известна заранее и задача состоит в том, чтобы заменить в сознании практикующего прежнюю «не доктринальную суть» на новую «доктринальную». Когда подобная операция производится над множеством объектов картины мира, то, в конце концов, возникает обновленное «релегитимированное мировоззрение», в полной мере реализующее принципы доктрины и соответствующим образом влияющее на самосознание практикующего адепта. Ведь теперь он получил убежденность не только в том, что воспринимаемым им мир есть иллюзия, но и в том, что он сам тоже является иллюзией. Разрыв, между восприятием и знанием ликвидирован, новый социокультурный гомеостаз обретен, и у человека, реализовавшего основной буддийский принцип «все есть пустота», 
исчезает противоречивость мотивов, и остается лишь одна мотивация: стремиться всеми силами к достижению самадхи для того чтобы войти в состояние нирваны и обрести буддовость. В ходе подобной практики меняется картина мира и личность человека, которая должна соответствовать обновленной картине мира.

Мы не станем входить в психологические тонкости процесса подобной трансформации, где подключаются процессы мышления, самовнушения, самоубеждения и т.д., тем более что подобные процессы до конца еще не изучены современной наукой. Для нас важно другое, найденная объясняющая концепция работает, значит, в рамках понимающей социологии создан теоретический аппарат, позволяющий рационально понять алгоритм целенаправленного изменения личности через изменение картины мира, при условиях изоляции альтернируемого субъекта от реальности его прежней социализации, с наличием у него мотивации к проведению процесса осознаваемой ресоциализации. С нашей точки зрения этого достаточно для понимания сути и содержания того, что происходит в ходе буддийской практики «безмятежного проникновения». Теперь можно ответить и на поставленные вопросы. В ходе указанной медитации происходит альтернация личности практикующих через ауторелегитимацию объектов картины мира, в результате чего осуществляется перестройка мировоззрения и самосознания практикующих. Если данный процесс релегитимации пройден успешно для адепта, то он, без сомнения, добивается заранее предсказанного результата - состояния буддийского самадхи, как гармонии между своим сознанием и новой, доктринально определенной картиной мира.

Возвращаясь к началу статьи, мы можем констатировать что, несмотря на существенные различия между восточным и западным дискурсом все-таки можно найти способы адекватного понимания восточных концепций, оставаясь в пределах европейского культурного кода.

\section{Сиисок литературы}

1. Бергер П.Л. Социальное конструирование реальности. Трактат по социологии знания / П.Л. Бергер, Т. Лукман. М.: Медиум, 1995. 
2. Неронов А.В. Новая нетрадиционная религиозность в культуре современной России: дисс. канд. культурологии: 24.00.01/ Неронов Александр Владимирович; Санкт-Петербургский государственный университет культуры и искусств. СПб., 2013.

3. Неронова М.Ю. Картина мира, идентичность и социокультурный гомеостаз / М.Ю. Неронова, А.В. Неронов. // Современные исследования социальных проблем (электронный научный журнал). №11(55). 2015. С. 211-224.

4. Цонкапа Чже. Ламрим - Большое руководство к этапам Пути Пробуждения в 5-ти томах. Перевод с тибетского языка А.Кугявичуса под общей редакцией А.Терентьева / Чже Цонкапа. СПб.: Нартанг, 1994. 2000.

5. Цонкапа Чже. Большое руководство к этапам пути пробуждения IV Этап духовного развития высшей личности (продолжение). Безмятежность (шаматха) - сущность медитации. Перевод с тибетского языка А.Кугявичуса под общей редакцией А.Терентьева / Чже Цонкапа. СПб.: Нартанг, 1998.

6. Чаттерджи С. Введение в индийскую философию / С. Чаттерджи, Д. Датта. М.: Изд-во Иностранной литературы, 1955.

7. Шохин В.К. Щербацкой и его компаративистская философия / В.К. Шохин. Research Support Scheme Electronic Library, 1999. [Электронный ресурс]. Режим доступа: http://www.e-lib.rss.cz, свободный.

8. Щербацкой Ф. И. Избранные труды по буддизму/Ф.И. Щербацкой. М.: Наука, 1988.

9. Щербацкой Ф.И. Теория познания и логика по учению позднейших буддистов. Часть II. Источники и пределы познания/ Ф.И. Щербацкой. СПб.: Изд-во АCTA-ПРЕCC LTD, 1995.

10. Щюц А. Избранное: Мир, светящийся смыслом / А. Щюц. М.: Российская политическая энциклопедия (РОССПЭН), 2004.

\section{References}

1. Berger P.L., Luckman T. Sotsial'noe konstruirovanie real'nosti. Traktat po sotsiologii znaniya [Social construction of reality. A treatise on the sociology of knowledge]. M.: Medium, 1995. 
2. Neronov A.V. Novaya netraditsionnaya religioznost'v kul'ture so-vremennoy Rossii: diss. kand. kul'turologii: 24.00.01 [New unconventional religiosity in the culture of modern Russia: Diss. Cand. Cultural Studies: 24.00.01]. SPb., 2013.

3. Neronova M.Yu., Neronov A.V. Sovremennye issledovaniya sotsial'nykh problem [Russian Journal of Education and Psychology]. No. 11 (55). 2015, pp. 211-224.

4. Tsongkhapa Jae. Lamrim - Bol'shoe rukovodstvo k etapam Puti Pro-buzhdeniya v 5-ti tomakh [Lamrim - A great guide to the stages of the Path of Awakening in 5 volumes]. Translation from the Tibetan language of A. Kugyavichus under the general edition of A. Terentyev. St. Petersburg: Nartang, 1994. 2000.

5. Tsongkhapa Jae. Bol'shoe rukovodstvo k etapam puti probuzhdeniya IV Etap dukhovnogo razvitiya vysshey lichnosti (prodolzhenie). Bezmyatezhnost'(shamatkha) - sushchnost' meditatsii [A great guide to the stages of the path of awakening. Stage IV of the spiritual development of a higher personality (continued). Serenity (shamatha) is the essence of meditation]. Translation from the Tibetan language of A. Kugyavichus, edited by A. Terentyev. St. Petersburg: Nartang, 1998.

6. Chatterjee S., Dutta D. Vvedenie v indiyskuyu filosofiyu [Introduction to Indian Philosophy]. M.: Publishing House of Foreign Literature, 1955.

7. Shokhin V.K. Shcherbatskoy i ego komparativistskaya filosofiya [Shcherbatsky and his comparative philosophy] / Research Support Scheme Electronic Library, 1999. [Electronic resource]. http://www.e-lib.rss.cz

8. Shcherbatskaya F.I. Izbrannye trudy po buddizmu [Selected Works on Buddhism]. M.: Nauka, 1988.

9. Shcherbatskaya F.I. Teoriya poznaniya i logika po ucheniyu pozdneyshikh buddistov. Chast'II. Istochniki i predely poznaniya [The theory of knowledge and logic in the teaching of later Buddhists. Part II. Sources and limits of knowledge]. SPb.: ACTA-PRESS LTD, 1995.

10. Schyuts A. Izbrannoe: Mir, svetyashchiysya smyslom [Selected: A world shining with meaning]. M.: Russian Political Encyclopedia (ROSSPEN), 2004. 


\section{ДАННЫЕ ОБ АВТОРАХ}

Неронова Марина Юрьевна, кандидат философских наук

Санкт-Петербургский государственный химико-фармацевтический университет

ул. Профессора Попова, 14А, г. Санкт-Петербург, 197022, Российская Федерачия marina.neronova@pharminnotech.com

Неронов Александр Владимирович, кандидат культурологии Санкт-Петербургский государственный химико-фармацевтический университет ул. Профессора Попова, 14А, г. Санкт-Петербург, 197022, Российская Федерация neronov58@mail.ru

\section{DATA ABOUT THE AUTHORS}

Neronova Marina Yuryevna, candidate of philosophical sciences St. Petersburg State University of Chemistry and Pharmacy 14A, Professor Popov Str., St. Petersburg, 197022, Russian Federation marina.neronova@pharminnotech.com

Neronov Alexander Vladimirovich, candidate of culturology St. Petersburg State University of Chemistry and Pharmacy 14A, Professor Popov Str., St. Petersburg, 197022, Russian Federation neronov58@mail.ru 